\title{
A coexistência do diverso em escolas católicas
}

\section{The coexistence of the diversity in catholic schools}

\author{
Aparecida Maria Almeida Barros ${ }^{1 *}$, Rafael Vasconcelos de Oliveira $^{2}$, Manoel Messias de \\ Oliveira $^{1}$
}

\begin{abstract}
RESUMO
Abordamos a coexistência do diverso enquanto um conjunto dos dispositivos institucionais que se mesclam quando da defesa de interesses distintos, sem polarizarem abertamente disputas por oposição. Por meio da coexistência do diverso, instituições e agentes públicos alargam as fronteiras dos discursos confessional e laico, religioso e cívico, em determinados espaços e tempos. Discutimos as marcas de um estado laico conduzido por agentes cristãos, evidenciando que a mesma sociedade laica também é cristã, as demandas convergem no atendimento de interesses tanto das instituições católicas quanto do estado republicando, a fronteira entre cristãos e cidadãos coexiste, mediada por acordos e afinidades, produzindo o que consideramos por coexistência do diverso. A cultura escolar configurada nas experiências institucionais, demarcaria os contornos e arranjos sociais, especialmente no empenho de subsídios públicos destinados às instituições. Na projeção das escolas para a sociedade, a ocorrência de atos cívicos e religiosos adaptados e combinados segundo as circunstâncias de cada realidade local e regional, nas quais materializam as existências e coexistências do diverso.
\end{abstract}

Palavras-chave: Escola católica; Cultura escolar; Coexistência; Religião; Estado.

\begin{abstract}
We approach the coexistence of the diversity as a set of institutional devices that merge when defending different interests, without openly polarizing disputes for the opposition. Through the coexistence of the diverse, institutions and public agents expand the boundaries of confessional and secular, religious and civic discourses, in certain spaces and times. We discuss the marks of a secular state led by Christian agents, showing that the same secular society is also Christian, the demands converge in meeting the interests of both Catholic institutions and the republican state, the boundary between Christians and citizens coexists, mediated by agreements and affinities, producing what we consider to be the coexistence of the diverse. The school culture configured in institutional experiences would demarcate the contours and social arrangements, especially in the use of public subsidies destined to institutions. In the projection of schools to society, the occurrence of civic and religious acts is adapted and combined according to the circumstances of each local and regional reality, in which the existence and coexistence of the diverse materialize.
\end{abstract}

Keywords: Catholic School; School Culture; Coexistence; Religion; State.

\footnotetext{
${ }^{1}$ Universidade Federal de Goiás, Regional Catalão/UFCat em transição.

*E-mail: cidaab@gmail.com

${ }^{2}$ IF Goiano Campus Urutai-GO
} 


\section{INTRODUÇÃO}

O estudo de instituições escolares laicas e confessionais vem proporcionando nas últimas décadas, contribuições no sentido de ampliar a produção de conhecimentos na História da Educação. A polissemia de temas e objetos, percebidos em diferentes tipos de fontes, tem aberto direcionamentos para diversas leituras e interpretações, como por exemplo, as disposições indiciárias da cultura escolar ${ }^{3}$. A discussão acerca de velhos temas, novos problemas e objetos, tem motivado novas descobertas, com a apreensão de relações diversas estabelecidas na esfera institucional, considerando determinações estruturais, organizacionais, epistêmicas, metodológicas, ritualísticas, cujas prescrições e experiências sugerem a dinâmica que denominamos por coexistência do diverso, transversalizada por dispositivos da cultura escolar. Por essa via, envidamos o mergulho nas fontes empíricas das instituições educativas católicas selecionadas nesta amostra, identificando eventos e situações que expressam a materialidade da coexistência do diverso enquanto possibilidade de reflexão.

Indicamos a percepção acerca do que denominamos de coexistência do diverso, cuja materialidade se reveste nas intenções e mediações estabelecidas pelos agentes em circunstancias particulares, nas quais se daríamos acordos e arranjos, terreno singular onde as práticas se efetivariam no sentido de configurar as relações de coexistência. Em seguida situamos as instituições escolares católicas, no recorte espaço-tempo-contexto, na rearticulação de poder da igreja instaurada em Goiás ao longo do século XX, com a colaboração de Congregações religiosas no comando de escolas.

No desdobramento de análise pontuamos as tramas e relações que evidenciam o modus operandi interno e externo da instituição com os agentes públicos e privados, no movimento de articulação das práticas que se caracterizariam, na nossa leitura, o diverso coexistente. Por fim, indicamos aspectos semelhantes, convergentes e distintivos identificados nas instituições, interpretados sob o referencial da cultura escolar.

Silva (2006), quando demarca distinções para cultura da escola, cultura escolar, cultura de escola, assim como cultura material da escola, fundamenta o campo conceitual para a compreensão da complexidade que envolve esse tema, inferindo referenciais e

\footnotetext{
${ }^{3}$ Esta temática, cuja discussão fora objeto de comunicação oral, com o título "a coexistência do diverso nos acordos e arranjos de instituições educativas católicas", (IX CBHE, João Pessoa-PB, 2017) gerou a publicação de um resumo estendido em versão provisória. Na sequência dos estudos, com ampliação de fontes e análises, produzimos o presente artigo em primeira edição original.
} 
autores com diversas enfoques e campos científicos. Ao explicitar a existência de uma cultura própria da escola, a autora indica como elementos protagonistas dessa materialidade: "os atores, os discursos e linguagens e as práticas”. (SILVA, 2006, p. 202).

O modo de organização, a concepção, os fins e objetivos diferem esta instituição de outras organizações sociais, por ser "uma instituição ímpar, que se estrutura sobre processos, normas, valores, significados, rituais, formas de pensamento, constituidores da própria cultura, que não é monolítica, nem estática, nem repetível." (SILVA, 2006, p. 205). É, pois, no âmbito da cultura escolar que enveredamos a discussão acerca da coexistência diverso em instituições confessionais católicas.

\section{COEXISTÊNCIA DO DIVERSO E CULTURA ESCOLAR}

Neste estudo, apreendemos a coexistência do diverso no plano da argumentação teórico-prático-reflexiva em movimento e em processo de elaboração. Evidenciar uma ocorrência que ainda não é um conceito no sentido estrito do termo, mas que poderá vir a ser, em se confirmando as generalizações e variáveis. Ao assumir esse caráter de uma prática que não está assentada em um terreno sólido de um campo científico (sociologia, filosofia, psicologia, história, por exemplo) reconhecido, estamos entendendo nesse momento, a coexistência do diverso, enquanto exercício de experiência concreta, cuja sustentação e solidez dar-se-ia na intencionalidade da ação que a movimenta e a impulsiona no sentido de se estruturar em situações específicas - quais sejam, no interior de acordos e arranjos firmados por entes e instituições que, embora não necessariamente alinhados pelos mesmos interesses, se aproximam com intenções distinta defendidas por ambas as partes. Essa é a ideia em construção. Diferentes agentes, com propósitos e finalidades distintas, se aproximam, coexistem, ocupam o mesmo cenário, cada qual defendendo interesses que lhes são peculiares.

Coexistência do diverso ainda não é um conceito estabelecido em um campo do conhecimento específico, mas em processo de elaboração reflexiva. Ao se expressar na percepção de aspectos gerais e específicos, pela ação de atores, de instituições e de práticas, é passível de ser identificado em circunstâncias determinadas, quando deriva ocorrências cujas relações são motivadas por interesses distintos de dois ou mais agentes.

Nesta configuração, ao tecer nexos com as disposições da cultura escolar temos que 
A cultura perpassa todas as ações do cotidiano escolar, seja na influência sobre os seus ritos ou sobre a sua linguagem, seja na determinação das suas formas de organização e de gestão, seja na constituição dos sistemas curriculares. (SILVA, 2006, p. 202).

Logo, o diverso coexistente estaria intrínseco à cultura escolar, movimentado em diferentes tempos e espaços, por interesses defendidos e acordados por agentes e instituições, os quais, embora distintos, não polarizam conflitos, ao contrário, pactuam relações de coexistências enquanto perdurarem a convergência dos respectivos interesses. Em outras palavras, pela coexistência do diverso, os dispositivos institucionais, em determinadas circunstâncias, ao invés de polarizarem os interesses em sentidos opostos, por exemplo, os agentes do estado laico, os representantes de instituições católicas e da hierarquia da igreja, investiriam em acordos que neutralizaria concorrência, disputa ou conflito, preconizado no alinhamento de interesses distintos. Ao contrário de demarcarem trincheiras por oposição, em determinadas circunstâncias, sob o argumento de um acordo formal, defende projetos distintos.

Entendendo que os interesses distintos das instituições escolares católicas e/ou de seus representantes versam sobre os princípios morais, religiosos e sociais defendidos pela igreja, em outras épocas os dispositivos da cultura escolar dessas instituições eram, substancialmente, a Bíblia Sagrada, livros religiosos e de Educação Moral e Cívica e aulas com conteúdos substancialmente conservadores. Todavia, atualmente é maior a presença de dispositivos móveis e da internet como recursos para a vida escolar. Em outras palavras, essa presença de dispositivos moveis é o resultado de uma cultura digital da atual sociedade.

Lopes e Valdemarin (2017) explicam que o sistema educacional sempre esteve atrelado ao progresso da humanidade, tendo apropriado do termo cultura como forma de normatizar seus procedimentos. No Brasil, por exemplo, a Lei de Diretrizes e Bases da Educação Nacional (Lei $n^{\circ}$ 9.394/96) orienta o princípio “da liberdade de aprender, ensinar, pesquisar e divulgar a cultura". Logo, a cultura entendida enquanto suporte para as apropriações e produções humanas ser fundamental "para o entendimento do cotidiano digital e também dos novos processos instalados dentro de sala de aula" (p.2).

A coexistência do diverso apreendida nas escolas católicas na dimensão da cultura escolar tipifica relações entre a escola e a sociedade nas quais se expressam acordos e arranjos que demarcam as trajetórias e as visões de mundo de ambas. Assim, Lopes \& Valdemarin (2017) ressaltam: trabalhar a coexistência do diverso de forma paralela com a cultura escolar demanda refletir sobre a sociedade contemporânea e a relação de novos 
hábitos do cotidiano que refletem nas práticas culturais, influenciando as tradições e unificando comportamentos recorrentes.

\section{ESCOLAS CATÓLICAS: INTERESSES COEXISTENTES}

Azzi (1994) indica que por volta da terceira década do estado laico republicano ocorreram as primeiras iniciativas de rearticulação da Igreja com o Estado, orquestradas por diferentes estratégias de ambas as partes.

Enquanto "o poder público via na igreja um valioso apoio para a manutenção da ordem pública (...). A Igreja, por sua vez, se considerava como elemento importante no país para a manutenção da ordem constituída através da pregação de valores morais religiosos" (AZZI, 1977, p.100).

O processo ao qual denominamos de movimento de restauração católica, cujas peculiaridades são distintas em cada estado da federação, apropria-se abertamente de tais premissas para firmarem acordos e arranjos locais, tendo em vista interesses de ambas as partes. Nesse sentido,

A finalidade específica do movimento de restauração católica era que, através do apoio e prestígio político, a Igreja pudesse atuar mais amplamente na sociedade, fazendo com que o catolicismo, que fora durante quatro séculos a religião oficial do Brasil, continuasse a ditar as normas morais e religiosas do país. (AZZI, 1977, p.101)

Em Goiás, a liderança do arcebispo Dom Emmanuel Gomes de Oliveira é expressiva na mediação e estreitamento dos canais de diálogo com o estado republicano, especialmente quando a educação católica é coloca na pauta de tais interesses. Durante o seu bispado, "o bispo da instrução", segundo Menezes (2001), utilizou-se de sua projeção junto aos governos estaduais e municipais, para o empenho de subvenções e doações em espécie, oriundas de recursos públicos e particulares, tendo em vista estruturar e ampliar a rede escolar católica, sob diferentes formatos e convênios.

Dom Emmanuel sempre incentivou a criação de escolas paroquiais, nas diversas paróquias de sua diocese. Aprendeu a dar valor a essas escolas com os americanos, pois, nos Estados Unidos, juntamente com a instalação de uma paróquia, costumam construir a casa paroquial e, ao lado, a escola paroquial. (MENEZES, 2001, p. 99) 
Nos limites deste estudo, extraímos circunstâncias, envolvendo duas instituições educativas católicas, nas quais se verificam indicadores da coexistência do diverso materializada em eventos e situações distintas.

Comecemos por esboçar na literatura específica alguns indicadores da cultura escolar:

\begin{abstract}
A cultura escolar é um artefato histórico, inventado e reinventado a partir de tensões e concessões provisórias entre proposições cognitivas entranhadas de relações de poder. Desta forma, as instituições escolares operam recortes específicos no conhecimento gerado pela sociedade, de modo que, a partir de critérios políticos e culturais, alguns saberes são selecionados e ressignificados para uso escolar. (DALABRIDA, 2012, p. 178)
\end{abstract}

Considerados os aspectos históricos educacionais, tal definição se aplica às particularidades de instituições educativas católicas, enquanto porta-vozes de uma formação atravessada por rituais, práticas, normas internas e eventos externos, com a finalidade de inculcar modos de vida, hábitos sociais e religiosos, são marcas da cultura escolar católica inscrita em diferentes instituições, sob o comando de ordens e/ou congregações religiosas.

Quanto aos representantes oficiais, ocorre a aproximação com vistas a afirmação de interesses de ambas as partes:

Igreja e Estado interessaram-se mutuamente pelo restabelecimento de antigas alianças que, por um lado, alimentavam o desejo do Estado de obter legitimação de seu poder com o aval da Igreja e, por outro, a Igreja esperava que o estado se tornasse um instrumento que colaborasse no regresso de seu prestígio e de sua ação na sociedade brasileira. Assim, a Igreja traçou estratégias de convivência como novo regime e formas de mútuo apoio que garantissem os interesses das duas instituições. (BENCOSTA, 2014, p. 395)

A combinação de interesses religiosos e cívico-sociais em eventos nos quais as escolas têm participação distintiva, podem ser apontados como circunstâncias em que a coexistência do diverso se expressa com vigor, haja vista a mobilização interna das instituições, aliada a outras hierarquias e autoridades civis, militares e religiosas.

No decorrer do ano letivo, as festas cívicas, representadas por datas comemorativas oficiais, assim como as festividades religiosas, celebradas no calendário litúrgico da igreja, oportunizam a realização de eventos nos quais a duplicidade de interesses é evidenciada de modo expressivo por diferentes agentes, em geral com a colaboração e participação da comunidade externa - pais, associações e agremiações. Nessa acepção, "Os representantes dos poderes civil e eclesiástico, apesar de desempenharem funções em esferas bem definidas, intercruzam seus interesses conforme 
as conveniências de ambos, como a questão do patriotismo cívico-escolar em ambiente católico". (BENCOSTA, 2014, p. 398)

Da igreja institucionalizada, semelhante expectativa de projeção, assim como a afirmação do poder local - com as paróquias e escolas - do poder regional, por meio da instalação de diferentes dioceses no âmbito dos estados. Semelhante movimento de aproximação também ocorre por parte dos governos estaduais ao incluírem nos cerimoniais e atos públicos a presença de lideranças eclesiásticas.

Durante as décadas do segundo quartel do século $\mathrm{XX}$, as escolas paroquiais franciscanas em Goiás vivenciaram oportunidades de exposições públicas, por ocasião de festividades diversas, nas quais a dupla finalidade cívica e religiosa tivera ampla difusão. Nos anos de chumbo do governo político-militar no Brasil, nos pós-1964, uma escola paroquial vinculada a uma diocese no sudeste goiano, seja pelo seu caráter misto - escola católica subvencionada por recursos públicos do estado, também foi palco onde semelhantes expressões foram vivenciadas.

Nas duas amostras, explicitaremos as diversas formas que as instituições assumiram na conformação de arranjos e acordos que evidenciaram a coexistência do diverso - no caso, o atendimento de interesses cívicos - almejados pelo estado laico, assim como os interesses religiosos, concebidos pelas ordens religiosas no comando das respectivas instituições. Segundo Bencosta:

\footnotetext{
Diante da lenta constituição de um sistema de educação de caráter laico e universal, as instituições educacionais católicas não deixaram de preparar os filhos "ilustres" da República para assumirem os principais postos na estrutura político-burocrática do novo regime, experiência que elas souberam acumular ao longo de séculos, inculcando e moldando nas mentes de seus alunos valores de uma cultura religiosa escolar capaz de marcar profundamente suas formações, ao ponto desta ser percebida em suas vidas adultas. (BENCOSTA, 2014, p. 402)
}

Originalmente as escolas paroquiais franciscanas, instaladas em diferentes municípios do sudeste goiano conservaram o mesmo formato organizacional e pedagógico. Os frades menores da Província do Santíssimo Nome de Jesus de Nova York, gerenciavam os processos para a instalação física das instituições, assumiam a direção escolar, enquanto a coordenação pedagógica e demais aspectos da funcionalidade interna ficavam sob a responsabilidade das irmãs franciscanas de Allegany.

Estes franciscanos e franciscanas, vindos dos Estados Unidos implantaram em Goiás, juntamente com as paróquias e ações filantrópicas, diversas instituições escolares 
- as escolas paroquiais e os Colégios. Nas Escolas franciscanas, a aplicação dos métodos ativos, inspirados na "moderna pedagogia americana", embalava as exposições, declamações e exibições públicas. Almeida Barros (2010) configura, em linhas gerais, a finalidade da escola paroquial franciscana em Goiás:

\begin{abstract}
A instituição escolar é percebida como o lugar onde a criança, além de ser introduzida à cultura letrada, também é uniformizada, é catequizada na fé cristã, na participação da liturgia da missa e dos sacramentos; é inserida em outros rituais da vida social e religiosa, que diferem dos costumes e crenças locais e regionais. Afinal, além de instruir e educar 'a grande massa dos incultos', também seria necessário empreender ações no sentido de retirar desse povo as práticas pagãs, entronizá-los nos rituais da fé católica. Assim, ambas as instituições, a igreja (o altar) e a Escola (a sala de aula), pelas mãos franciscanas, assumem a função de catequizar e alfabetizar, num projeto articulado de civilizar, instruir e sacralizar a não. A reinterpretação das práticas religiosas locais introduz os dogmas da Igreja romana e revitaliza o culto católico através dos sacramentos e a observância da virtude e da caridade. (ALMEIDA BARROS, 2010, p.75-76)
\end{abstract}

Configurada nas intenções de abrangência interna e externa, a escola paroquial visa a formação cívica e religiosa das crianças, recorrendo a estratégias distintas, onde se operacionalizava o cultivo de hábitos litúrgicos e cívicos. É recorrente observar que, enquanto o altar é representativo da igreja institucionalizada, a partir da sala de aula se promove a mediação do aprendizado com a vida social dessas crianças, futuras lideranças da boa sociedade católica.

Ao assumir essa dupla finalidade, por meio da instituição escolar, a igreja promove a rearticulação de afirmação e poder legitimada pela sociedade que, enxerga nessa instituição um espaço de formação disciplinar, ordeira e pacífica.

\footnotetext{
A busca por uma colaboração estável com o poder civil necessitava de estratégias que permitissem à Igreja aparecer como instituição fundamental nessa nova ordem. Nesse sentido, a cultura cívico-escolar de matriz católica contribuiu para que a hierarquia eclesiástica tratasse de temas e ações que impulsionassem a formação de elites capazes de se introduzir no aparato político em defesa dos interesses da instituição eclesiástica. Esse tipo de colaboração foi, de certo modo, recebido com entusiasmo pelo poder civil que, em plena transformação social, econômica e política do início do século XX, necessitava do apoio do poder eclesiástico para afirmar a nova ordem entre os setores populares. (BENCOSTA, 2014, p. 402)
}

$\mathrm{Na}$ escola paroquial diocesana, as estreitas relações firmadas entre a sociedade civil católica, com a chancela do vigário paroquial e representantes da secretaria de educação estadual são inscritas em diferentes atos, a começar pelo repasse de verba pública para a construção do prédio escolar em terreno de propriedade da diocese. A 
escola, embora identificada como paroquial, foi instalada como instituição pública, mantida pelo estado, com a contratação de professores e destinação de verbas para a sua manutenção, enquanto a direção fora assumida por professoras leigas, oriundas da sociedade católica local.

Segundo registros da crônica histórica, a Escola Paroquial "João XXIII"4, fundada em 1960, sendo a primeira instituição escolar confessional da cidade, pertencente à Paróquia do "Bom Jesus" de Urutaí-GO, com o empenho de leigos católicos, tinha por finalidade de alfabetizar adultos. No ano de 1963, um decreto-lei municipal, oficializa a criação da escola pública municipal, com início das atividades previstas para o mês de março daquele ano. A designação de uma professora, contratada pelo município determina que a escola tenha funcionamento noturno, das 19:00 às 21:00. Na mesma lei ficam estabelecidos os cargos, funções e provimentos financeiros para a professora contratada.

Em caráter temporário, teve início o funcionamento nas dependências da casa paroquial; com a chegada de padres beneditinos dos EUA, a sala de aula fora deslocada para casas alugadas nas proximidades da igreja e da casa paroquial, tendo em vista melhorar as acomodações das atividades da escola. Cerca de nove anos depois, em 1969, o prédio escolar foi edificado em terreno onde funcionou a primeira capela do distrito, depois emancipado com o nome de Urutaí-GO.

Em correspondência entre o bispo da diocese ao prefeito municipal, quando da consulta oficial sobre a construção do prédio escolar, há indicativo sobre a origem da verba pública destinada à construção da escola: recursos provenientes do Plano Nacional de Educação, em convênio firmado pelo município. Na resposta a autoridade eclesiástica acolhe proposta e reconhece a importância da construção, menciona as cláusulas e exigências assumidas pela prefeitura municipal, por ocasião da assinatura do convênio programa, mas emite um posicionamento sobre as condições que a diocese impõe para o funcionamento e destinação da instituição escolar instalada em terreno paroquial.

$\mathrm{Na}$ referida correspondência o prelado é categórico quanto às suas condições: a direção da escolar seria indicada e assumida pelo pároco local e a autonomia quanto à destinação de uso do prédio e das dependências da escola pela igreja, no sentido de dispor

\footnotetext{
4 Ver mais sobre a Escola Paroquial "João XXIII" em: OLIVEIRA, Rafael Vasconcelos de. Escola Paroquial “João XXIII” de Urutai-GO (1960-2001) [Dissertação]. 2018.
} 
em benefício da comunidade. No desfecho da correspondência fica evidente a autoridade eclesiástica na decisão final a respeito do projeto, enfatizando que as exigências da diocese não serviriam de embaraço para o andamento das obras.

Efetivada a construção do prédio e a instalação da escola em espaço próprio, um requerimento do vigário paroquial, em 1977, formaliza ao secretário de estado da educação, o pedido para a instalação de 'um convênio permanente' para o funcionamento da escola, com recursos provenientes da educação estadual. Pelos registros consultados, desde a origem, a escola paroquial, embora instalada e dirigida por representantes da diocese e paróquia local, contaram com o aporte financeiro do município e do estado para custear as despesas alusivas à manutenção das atividades, incluindo as edificações físicas do prédio escolar.

Há momentos em que essa relação de dubiedade levanta dúvidas quanto à natureza mista da instituição - confessional - pública municipal - pública estadual. Embora os registros paroquiais demarcam a existência da escola para o início de 1960, oficialmente, a lei de criação, que a reconhece como instituição pública municipal é datada de abril de 1963, com efeito retroativo ao mês de março do referido ano. No decorrer dos anos de 1970, quando ocorre a celebração de convênios com a educação estadual, supõe-se que a instituição tenha alterado essa vinculação, passando de entidade pública municipal para entidade pública estadual.

Sejam quais tenham sido as circunstâncias em que igreja e poder público tenham firmado acordos e convênios, a natureza mista da escola paroquial fica evidente, principalmente quanto à origem dos proventos e subsídios que a mantém em funcionamento. Por quase quatro décadas funciona como instituição dirigida pela igreja ou por profissionais indicados segundo o perfil religioso, com recursos de origem pública - seja municipal ou estadual.

\section{CULTURA ESCOLAR: IMPLICAÇÕES NA EDUCAÇÃO E NAS INSTITUIÇÕES CATÓLICAS}

Definir "cultura" não é uma tarefa simples, tendo em vista que a palavra está repleta de significados multidisciplinares, sendo utilizada para subsidiar estudos em várias áreas, metodologias e usos, na compreensão de que a cultura, de forma geral, perpassa por diferentes setores do cotidiano humano. Na verdade, o termo cultura tem 
sido usado por outros campos como, por exemplo, de cultura organizacional, de cultura política etc. (LOPES \& VALDEMARIN, 2017).

Assim sendo, são diversos os conceitos de "cultura' na atualidade e o termo acompanha vários universos dependendo do contexto a que está ligada, o que a torna, ora como algo individual, ora como fator coletivo. Com relação à cultura escolar, concordamos com Forquin (1993) ao evidenciar que,

\begin{abstract}
Incontestavelmente, existe, entre educação e cultura, uma relação íntima e orgânica. Quer se tome a palavra "educação" no sentido amplo, de formação e socialização do indivíduo, quer se restrinja unicamente ao domínio escolar, é necessário reconhecer que, se toda a educação é sempre educação de alguém, por alguém, ela supõe também, necessariamente a comunicação, a transmissão, a aquisição de alguma coisa: conhecimentos, competências, crenças, hábitos, valores, que constituem o que se chama precisamente de "conteúdo" da educação. Devido ao fato de que este conteúdo parece irredutível ao que há de particular e contingente na experiência subjetiva ou intersubjetiva imediata, constituindo, antes, a moldura, o suporte e a forma de toda experiência individual possível, devido, então, a que este conteúdo que se transmite na educação é sempre alguma coisa que nos procede, nos ultrapassa, nos institui enquanto sujeitos humanos pode-se perfeitamente dar-lhe o nome de cultura. (FORQUIN, 1993, p. 10)
\end{abstract}

Ao considerar essa relação entre educação e cultura materializada nos conteúdos da educação, a transmissão do conhecimento, crenças, hábitos e valores que são repassados na escola, conforme o autor, o protagonismo de agentes internos à escola, tais como gestores, diretores, coordenadores, enfim, representantes oficiais das escolas católicas, e dos agentes externos, representados por lideranças e autoridades de estado, em cargos e funções públicas que, na convergência de interesses, encaminhariam ações no sentido de respaldar a funcionalidade institucional em diferentes temporalidades.

Para Vinao Frago,

[...] esses modos de fazer e de pensar - mentalidades, atitudes, rituais, mitos, discursos, ações - amplamente compartilhados, assumidos, não postos em questão e interiorizados, servem a uns e a outros para desempenhar suas tarefas diárias, entender o mundo acadêmico-educativo e fazer frente tanto às mudanças ou reformas como às exigências de outros membros da instituição, de outros grupos e, em especial, dos reformadores, gestores e inspetores (VIÑAO FRAGO, 2000, p. 100)

Nessa diretiva, cada escola tem sua cultura definida de acordo com o sistema educacional a que pertence, isto é, também tem uma cultura institucionalizada a qual se expressa por meio da compreensão de que "as normas de comportamento escolar não foram geradas como algo autônomo, ainda que a escola elabore seus próprios ritos, tem 
relação com os valores sociais [...] dos indivíduos nos processos sociais" (GIMENO SACRISTÁN, 1998, p. 132).

\begin{abstract}
A cultura escolar apresenta-se assim como uma cultura segunda com relação à cultura de criação ou de invenção, uma cultura derivada e transposta, subordinada inteiramente a uma função de mediação didática e determinada pelos imperativos que decorrem desta função, como se vê através destes produtos e destes instrumentos característicos constituídos pelos programas e instruções oficiais, manuais e materiais didáticos, temas de deveres e de exercícios, controles, notas, classificações e outras formas propriamente escolares de recompensas e de sanções. (FORQUIN, 1993, p. 33-34)
\end{abstract}

No seio da cultura escolar há possibilidades de reinvenção das práticas escolares, de concepções, assim como a significação de diversos eventos, considerando que no interior da escola que se materializa variadas ações de natureza cultural, política e pedagógica, onde são protagonizadas resistências por gestores e professores às mudanças, além de forjarem alterações efetuadas nos padrões de trabalho vigentes (FARIA FILHO et. al. 2004).

Para estes autores, a cultura escolar tem o potencial de subsidiar as análises históricas, conferindo visibilidade na estruturação propriamente dita de eventos do campo que decidem analisar os estudos em história da educação. Evidencia-se uma cultura escolar permeada por práticas educacionais que marcam a intencionalidade da relação educação e cultura no corpo da educação, de forma geral. Práticas educacionais e/ou que ocorrem no interior das escolas que materializam saberes, conhecimentos e currículos; espaços, tempos e instituições escolares; materialidade escolar e métodos de ensino, tratando os costumes e a criatividade de seus atores e, a forma lúdica de se tratar conteúdos populares e interativos, por exemplo, as datas comemorativas que compõem o calendário escolar.

Ao situar o objeto de estudo, qual seja, a coexistência do diverso em escolas católicas, é conveniente visualizar uma trama complexa estabelecida na relação entre cultura e escola, no modo como os acordos e arranjos determinam relações da escola com a sociedade em diferentes escalas. No entendimento de que, em diferentes temporalidades, a instituição igreja católica exerceu sua influência religiosa e propagou seus ideais através da educação comungando com o Estado brasileiro na convergência de práticas, considerando que as instituições escolares católicas não têm uma cultura escolar livre de subvenções a quaisquer atividades religiosas (LOPES \& VALDEMARIN, 2017). 
Ao perceber a ação dos agentes das instituições e do estado laico, na demarcação de interesses e relações coexistentes, evidenciamos distinções e particularidades da composição do laicidade, assim como a participação dos atores religiosos nos limites de decisões e composições com o poder público em diferentes unidades federadas, indicando ações estabelecidas conforme os interesses e conveniências. Neste sentido, ações como doação de área da igreja para edificação de escola com recursos provenientes do erário público, a captação de subsídios para fomentar programas e projetos, assim como a indicação de cargos e funções para o funcionamento interno, teriam um caráter misto operacionalizado por agentes da igreja e do estado, assegurando a existência escolar, assim como a instalação de projetos e programas formativos distintos.

\section{CONCLUSÕES}

As escolas investigadas possuem em comum a localização geográfica, com municípios situados no sudeste goiano, são denominadas escolas paroquiais, porém conservam distinções no formato, na natureza institucional e no modelo escolar. Ambas tiveram a colaboração de religiosos americanos durante determinados períodos, sendo que no decorrer das décadas ocorreu o gradativo repasse para a direção de leigos católicos. Nos demais aspectos são singulares, são distintas quanto ao modo de organização e estruturação internas.

[...] a escola é uma instituição da sociedade, que possui suas próprias formas de ação e de razão, construídas no decorrer da sua história, tomando por base os confrontos e conflitos oriundos do choque entre as determinações externas a ela e as suas tradições, as quais se refletem na sua organização e gestão, nas suas práticas mais elementares e cotidianas, nas salas de aula e nos pátios e corredores, em todo e qualquer tempo, segmentado, fracionado ou não. (SILVA, 2006, p. 206)

Ao materializar o que compreendemos por coexistência do diverso, observamos que nas instituições ocorrem interesses distintos que propiciam as condições de existência das escolas. No nosso entendimento, a apropriação do projeto catequético franciscano não se realizaria de maneira uniforme, haveria adesões, acordos e resistências típicas do processo de apropriação da cultura religiosa institucionalizada e de uma instrução escolar fundada na ética e nos valores cristãos católicos. (ALMEIDA BARROS, 2010, p. 87-88). Em se tratando de populações urbanas e rurais (com predomínio da última), marcadas por práticas e costumes locais, cada fração de classe possuiria os seus próprios códigos a 
partir dos quais seriam processadas as diferentes possibilidades de assimilação e adesão aos bens simbólicos. (ALMEIDA BARROS, 2010, p. 87-88).

As relações entre a Igreja institucionalizada e o Estado laico republicano, são cultivadas em diferentes circunstâncias, tendo em pauta assuntos de interesse das instituições escolares. A coexistência de acordos entre o Estado e a Igreja, com representação da hierarquia diocesana, pode ser verificada em casos de negociação de espaços físicos e do empenho de recursos financeiros para subsidiar ações educativas. Ainda que pairem dúvidas quanto a interferência direta na definição do currículo escolar, essas negociações foram profícuas e compuseram um interessante capítulo sobre os acordos firmados no âmbito das dioceses, paróquias e autoridades republicanas. Ademais, embora as primeiras décadas republicanas tenham sido caracterizadas por alguns historiadores da educação em Goiás, retratando uma realidade decadente, de povo analfabeto e 'inculto', aspectos também reforçados em alguns registros dos missionários americanos, havia uma cultura escolar em curso, a instrução pública nos grupos escolares e nas escolas isoladas e outra que chegava, se impunha com vigor e acolhimento pela sociedade católica, as escolas paroquiais.

A ênfase na propagação de padrões, resultados e produções das escolas, por meio de eventos sociais, com a presença e prestígio de agentes de estado, igualmente indicaria o alinhamento de interesses convergentes, na expressão da coexistência do diverso, enquanto elemento aglutinador de ações.

Ao fundamentar em referências de pesquisas produzidas, sinalizamos ter observado semelhantes disposições nas escolas denominadas paroquiais, seja na organização interna, na gestão e na relação externa, demonstram haver dispositivos coexistentes. Discutimos as marcas de um estado laico conduzido por agentes cristãos. A mesma sociedade laica também é cristã, as demandas convergem no atendimento de interesses tanto das instituições católicas quanto do estado republicando, a fronteira entre cristão e cidadão coexiste, mediada por acordos e afinidades. A cultura escolar configurada nas experiências institucionais, demarcaria os contornos de arranjos sociais, circulação de ideias, assim como atos cívicos e religiosos adaptados e combinados segundo as circunstâncias de cada realidade local e regional, nas quais materializam as existências. 


\section{REFERÊNCIAS}

ALMEIDA BARROS, A. M. No Altar e na Sala de Aula: vestígios da Catequese e Educação Franciscanas no sudeste goiano (1944-1963). 465 f. 2010. Tese. (Programa de Pós-graduação em Educação - doutorado). Universidade Federal de São Carlos, São Paulo, 2010.

AZZI, R. O Estado leigo e o projeto ultramontano. São Paulo: Paulus, 1994.

AZZI, R. O Início da Restauração Católica no Brasil - 1920-1930 (II). Síntese, BH, 1977.

BENCOSTA, M. L. Cultura cívico-escolar católica e desfiles patrióticos no Brasil do início do século XX. VARIA HISTORIA, Belo Horizonte, vol. 30, n 53, p.391-403, mai./ago. 2014.

DALABRIDA, N. Cultura Escolar Católica, elitista e masculina. Revista Lusófona de Ciência das Religiões -ANO XI,2012/n.16/17-177-192. Disponível em: https://revistas.ulusofona.pt/index.php/cienciareligioes/article/view/3820. Acesso em: 15 set. 2021.

FARIA FILHO, L. M. de. et all. A cultura escolar como categoria de análise e como campo de investigação na história da educação brasileira. Educação e Pesquisa. Vol.30. Núm.1, p. 139-159, São Paulo: jan./abr. 2004. Disponível em: https://www.scielo.br/j/ep/a/gWnWZd8C5TsxsYC7d6KzbTS/?lang=pt. Acesso em: 15 set. 2021.

FORQUIN, J. C. Saberes escolares, imperativos didáticos e dinâmicas sociais. Teoria \& Educação. Núm. 5. Porto Alegre/RS, n. 6, p. 49-28, 1992.

FORQUIN, J. C. Escola e Cultura: a sociologia do conhecimento escolar. Porto Alegre: Artes Médicas, 1993.

KULESZA, Wojciech Andrzej. A cultura escolar católica no Brasil moderno. Educação UNISINOS -Revista do Programa de Pós-Graduação em Educação da Universidade do Vale do Rio dos Sinos. São Leopoldo, v.8, n.14, p.189-204, jan. /jun./2004.

LOPES, E. E. Ferreira \& VALDEMARIN, V. T. Cultura escolar contemporânea e o uso dos dispositivos moveis e internet. Anais. I Seminário de Políticas Públicas e Desenvolvimento Territorial. Araraquara, 2017.

MAGALHÃES, J. P. de. Tecendo nexos: história das instituições educativas. Bragança Paulista, SP: Editora Universitária São Francisco, 2004.

MENEZES, Á. C. de. Dom Emmanuel Gomes de Oliveira, o arcebispo da Instrução. Goiânia-GO., Agepel, 2001.

OLIVEIRA, R. V. de. Escola Paroquial “João XXIII” de Urutaí-GO (1960-2001). 239 f. 2018. Dissertação. (Programa de Pós-graduação em Educação - mestrado). Universidade Federal de Goiás, Regional Catalão-GO, 2018. 
SILVA, F. de C. T. Quadro conceitual e Possibilidades de Pesquisa. Revista Educar, Curitiba, n. 28, p. 201-216, 2006. Editora UFPR. Disponível em: https://www.scielo.br/j/er/a/w6kJ5hdSGVRnhRWTVP68D3P/?lang=pt\&format=pdf.

Acesso em: 15 set. 2021.

VIÑAO-FRAGO, A. Historia de La educación e historia cultural: possibilidades, problemas, cuestiones. Revista Brasileira de Educação, (0), 63-82, 1995. Disponível em:

http://anped.tempsite.ws/novo_portal/rbe/rbedig1ital/RBDE0/RBDE0_06_ANTONIO\% 20VINAO_FRAGO.pdf Acesso em: 10 ago. 2021.

VIÑAO-FRAGO, A. El espacio y el tiempo escolares como objeto histórico. WARDE, M. J. (org.). Contemporaneidade e Educação. Temas de História da Educação. Rio de Janeiro: Instituto de Estudos da Cultura da Educação, 2000. 